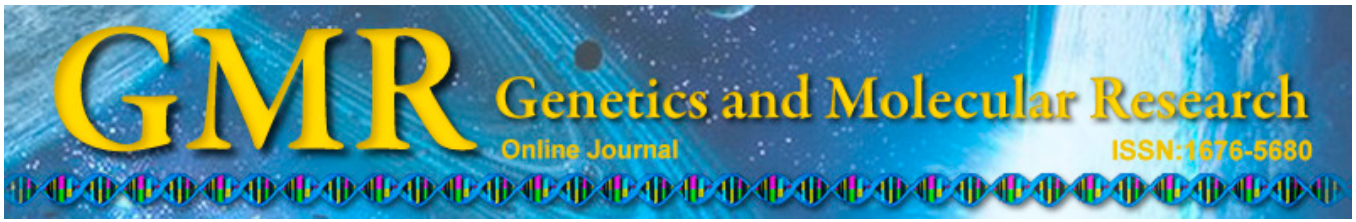

\title{
Protein expression levels in the medullary visceral zone of rats with subarachnoid hemorrhage
}

\author{
L.H. Sun ${ }^{1,2}$, L.F. Xing ${ }^{3}$, G.H. Zhang ${ }^{2}$ and S.Y. Pan $^{1}$ \\ ${ }^{1}$ Department of Neurology, Nanfang Hospital, \\ Southern Medical University, Guangzhou, China \\ ${ }^{2}$ Department of Neurology, \\ The Affiliated Hospital of Inner Mongolia Medical University, Hohhot, China \\ ${ }^{3}$ Department of Neurology, The China Ordnance Northern Heavy Group Hospital \\ (The Third Affiliated Hospital of Baotou Medical College), Baotou, China \\ Corresponding author: S.Y. Pan \\ E-mail: pansuyuedn@126.com
}

Genet. Mol. Res. 14 (3): 8839-8846 (2015)

Received November 17, 2014

Accepted April 6, 2015

Published August 3, 2015

DOI http://dx.doi.org/10.4238/2015.August.3.7

\begin{abstract}
We investigated protein expression in the medullary visceral zone (MVZ) of rats with multiple-organ dysfunction syndrome (MODS) caused by subarachnoid hemorrhage (SAH) to discuss the possible regulatory mechanism of the MVZ in the course of SAHinduced MODS. A SAH-induced MODS model was established in rats by injecting arterial blood into the Willis' circle. Protein expression in the MVZ was analyzed by immunohistochemistry assay. Protein expression in the MVZ peaked 24-36 h after SAH, and was significantly higher than in the control and sham operation groups. Organs at each time point exhibited inflammatory injuries to varying degrees after $\mathrm{SAH}$, which reached a maximum at 24-36 h. Incidences of systemic inflammatory response syndrome and MODS were 100 and $71.67 \%$, respectively, after SAH. There is a consistency between MVZ protein expression and inflammatory changes in each organ after SAH. This
\end{abstract}


prompts the suggestion that the MVZ may be one of the direct regulative centers in SAH-induced MODS, and may be involved in the functional regulation of the surrounding organs after $\mathrm{SAH}$.

Key words: Subarachnoid hemorrhage; Medullary visceral zone; Rat model; Protein expression; Multiple-organ dysfunction syndrome

\section{INTRODUCTION}

The mechanisms of systemic inflammatory response syndrome (SIRS) and multipleorgan dysfunction syndrome (MODS) caused by acute cerebrovascular disease (ACVD) have not been fully elucidated either in China or internationally (Whiteley et al., 2011; Koton et al., 2012). In the past, research has focused on the hypothalamus. In particular, a series of studies have been carried out on changes of the neuroendocrine function of the hypothalamicpituitary-target gland axis in the course of ACVD-induced MODS (Arauz et al., 2010; Yavuz et al., 2012). Recent studies have found that a structural function region called the medullary visceral zone (MVZ), located in the middle and tail of the medulla oblongata, participates in the regulation of visceral activities under various stress states. However, whether the MVZ is also involved in the process of MODS caused by ACVD has rarely been reported (Rösler et al., 2010; Abdo et al., 2012).

According to the diagnostic criteria of SIRS and MODS for laboratory animals, we successfully established an animal model for MODS induced by subarachnoid hemorrhage (SAH) in the early stage. We used the model to explore the central regulative role of the MVZ in the functions of the surrounding organs after SAH by observing protein expression in the MVZ of the model rats. Our objective was to provide a new theoretical and experimental basis for the clinical prevention of ACVD-induced MODS.

\section{MATERIAL AND METHODS}

\section{Animal grouping}

Eighty healthy adult male Wistar rats (clean-grade) weighing 200-220 g were provided by the SLRC Laboratory Animal Co., Ltd., Shanghai, China. The rats were divided into a normal control group, a sham operation group, and six experimental subgroups of 10 rats each for observations at $6,12,24,36,48$, and $72 \mathrm{~h}$ following SAH using a random number table.

\section{Modeling}

The SAH-induced MODS model was established in the rats by injecting arterial blood into the Willis' circle (Ozel et al., 2009). Life signs of the rats at each time point were observed postoperatively, and blood routine, hepatic and renal function, and cardiac enzymes were detected. The tissues of the lung, liver, kidney, and small intestine were taken for pathological examination by hematoxylin and eosin staining. Protein expression in the MVZ was determined using the immunohistochemical $\mathrm{ABC}$ method after freezing sections of cerebral tissue. A set of medullary slices was randomly selected from each rat to calculate the sum of positive MVZ cells in the set of slices at a magnification of 20 (ocular lens) x 20 (objective lens). 


\section{Statistical analysis}

All data are reported as means \pm standard error and were analyzed by SPSS 13.0. The data were subjected to the $t$-test and analysis of variance. $\mathrm{P}<0.05$ was considered to be statistically significant.

\section{RESULTS}

\section{Vital signs and blood biochemical indices}

The differences in breathing, heart rate, body temperature, peripheral white blood cell count, alanine aminotransferase, aspartate aminotransferase, blood urea nitrogen, creatinine, and creatine kinase were not statistically significant between the sham operation group and the normal control group $(\mathrm{P}>0.05)$. The above indicators of the SAH group were all higher than those of the normal control group and the sham operation group $(\mathrm{P}<0.01$; Tables 1 and 2$)$.

Table 1. Basic data for animals.
\begin{tabular}{lcccc}
\hline Group & Respiratory rate $(\mathrm{bpm})$ & Heart rate $(\mathrm{bpm})$ & Body temperature $\left({ }^{\circ} \mathrm{C}\right)$ & WBC $\left(\times 10^{9} / \mathrm{L}\right)$ \\
\hline Normal & $59.42 \pm 2.16$ & $146.52 \pm 26.17$ & $35.92 \pm 0.64$ & $7.06 \pm 0.28$ \\
Sham operation & $60.18 \pm 2.32$ & $149.29 \pm 24.91$ & $36.04 \pm 0.59$ & $7.13 \pm 0.29$ \\
SAH & $107.81 \pm 9.16^{\# *}$ & $294.65 \pm 39.15^{\# *}$ & $39.48 \pm 0.81^{* *}$ & $18.46 \pm 2.61^{* *}$ \\
\hline
\end{tabular}

Data are reported as means \pm SE. bpm $=$ breaths (or beats) per minute; $\mathrm{WBC}=$ white blood cell count; $\mathrm{SAH}=$ subarachnoid hemorrhage. Compared with the normal group, ${ }^{*} \mathrm{P}<0.01$; compared with the sham operation group, ${ }^{*} \mathrm{P}<0.01$.

Table 2. Blood biochemical indices at each time point.
\begin{tabular}{lccccr}
\hline Group & ALT $(\mathrm{U} / \mathrm{L})$ & AST $(\mathrm{U} / \mathrm{L})$ & $\mathrm{BUN}(\mu \mathrm{M})$ & $\mathrm{Cr}(\mu \mathrm{M})$ & $\mathrm{CK}(\mathrm{U} / \mathrm{L})$ \\
\hline Normal & $64.58 \pm 9.12$ & $143.52 \pm 16.18$ & $5.89 \pm 0.87$ & $26.84 \pm 3.29$ & $692.25 \pm 39.46$ \\
Sham operation & $67.29 \pm 9.45$ & $146.82 \pm 15.64$ & $5.93 \pm 0.91$ & $28.56 \pm 3.81$ & $703.15 \pm 38.42$ \\
SAH & & & & \\
6 h & $76.49 \pm 10.61$ & $159.53 \pm 24.89$ & $7.92 \pm 1.06$ & $36.54 \pm 4.91^{\# *}$ & $953.55 \pm 61.98^{\mathrm{ab}}$ \\
$12 \mathrm{~h}$ & $159.29 \pm 26.14^{\# *}$ & $194.27 \pm 29.18^{\# *}$ & $15.57 \pm 2.64^{\# *}$ & $49.82 \pm 5.66^{\# *}$ & $1652.94 \pm 95.56^{\# *}$ \\
$24 \mathrm{~h}$ & $216.18 \pm 29.49^{\# *}$ & $299.54 \pm 39.15^{\# *}$ & $25.26 \pm 3.27^{* *}$ & $69.92 \pm 6.57^{\# *}$ & $1968.28 \pm 96.25^{\# *}$ \\
$36 \mathrm{~h}$ & $204.56 \pm 22.17^{\# *}$ & $261.59 \pm 29.68^{\# *}$ & $19.67 \pm 2.51^{\# *}$ & $60.68 \pm 5.91^{\# *}$ & $1539.67 \pm 89.26^{\# *}$ \\
$48 \mathrm{~h}$ & $142.38 \pm 16.28^{\# *}$ & $205.92 \pm 18.16^{\# *}$ & $14.65 \pm 2.09^{* *}$ & $52.94 \pm 4.68^{\# *}$ & $1256.26 \pm 76.16^{\# *}$ \\
$72 \mathrm{~h}$ & $97.46 \pm 12.57^{\mathrm{a}}$ & $177.84 \pm 13.58^{\mathrm{a}}$ & $8.99 \pm 1.67^{\mathrm{a}}$ & $39.19 \pm 4.46^{\mathrm{a}}$ & $991.58 \pm 71.65^{\mathrm{a}}$ \\
\hline
\end{tabular}

Data are reported as means $\pm \mathrm{SE}$. ALT $=$ alanine aminotransferase; $\mathrm{AST}=$ aspartate aminotransferase; $\mathrm{BUN}=$ blood urea nitrogen; $\mathrm{Cr}=$ creatinine; $\mathrm{CK}=$ creatine kinase; $\mathrm{SAH}=$ subarachnoid hemorrhage. Compared with the normal group, ${ }^{*} \mathrm{P}<0.01,{ }^{a} \mathrm{P}<0.05$; compared with the sham operation group, ${ }^{*} \mathrm{P}<0.01,{ }^{\text {b }} \mathrm{P}<0.05$.

\section{Incidence rates of SIRS and MODS in the SAH group}

The incidences of SIRS and MODS in the SAH group were 100 and $71.67 \%$, respectively. There were seven deaths before the time points, accounting for $11.67 \%$ of the rats in the SAH group.

\section{Pathological changes of main organs}

The histological structures of each organ in the normal control group and the sham 
operation group were basically normal. The lungs of the SAH group exhibited telangiectasia congestion, and exudation in alveolar space and perivascular area at $6 \mathrm{~h}$. Alveolar space was obviously expanded, and fibrin effusion was observed in the bronchial and tracheal cavities at $12 \mathrm{~h}$. Mild chronic lymphocytic bronchial pneumonia was found after 24 and $36 \mathrm{~h}$ (Figure 1A). The inflammatory change mentioned above was alleviated at $48 \mathrm{~h}$. Edema and thickening appeared in the mucosa and submucosa of the small intestine at $24 \mathrm{~h}$. Edema, thickening, congestion and mild inflammatory cell infiltration were observed between the muscular layer and the mucosal layer after 36 and $48 \mathrm{~h}$ (Figure 1B). Mucosal and submucosal congestion and edema occurred occasionally after $72 \mathrm{~h}$. Cloudy swelling was found in a small number of hepatocytes after $8 \mathrm{~h}$. Spotty necrosis of hepatocytes and hepatic sinusoid expansion were observed after $24 \mathrm{~h}$ (Figure 1C). A small amount of interstitial chronic inflammatory cell infiltration and acidophilic change of hepatocytes appeared after $36 \mathrm{~h}$, and was alleviated after $48 \mathrm{~h}$. Renal interstitial congestion began to occur and cloudy swelling of a few epithelial cells of the proximal renal tubule was found after $12 \mathrm{~h}$. Glomerular atrophy and renal tubular dilatation of varying degrees appeared after 24 and $36 \mathrm{~h}$ (Figure 1D), which were alleviated after $48 \mathrm{~h}$.

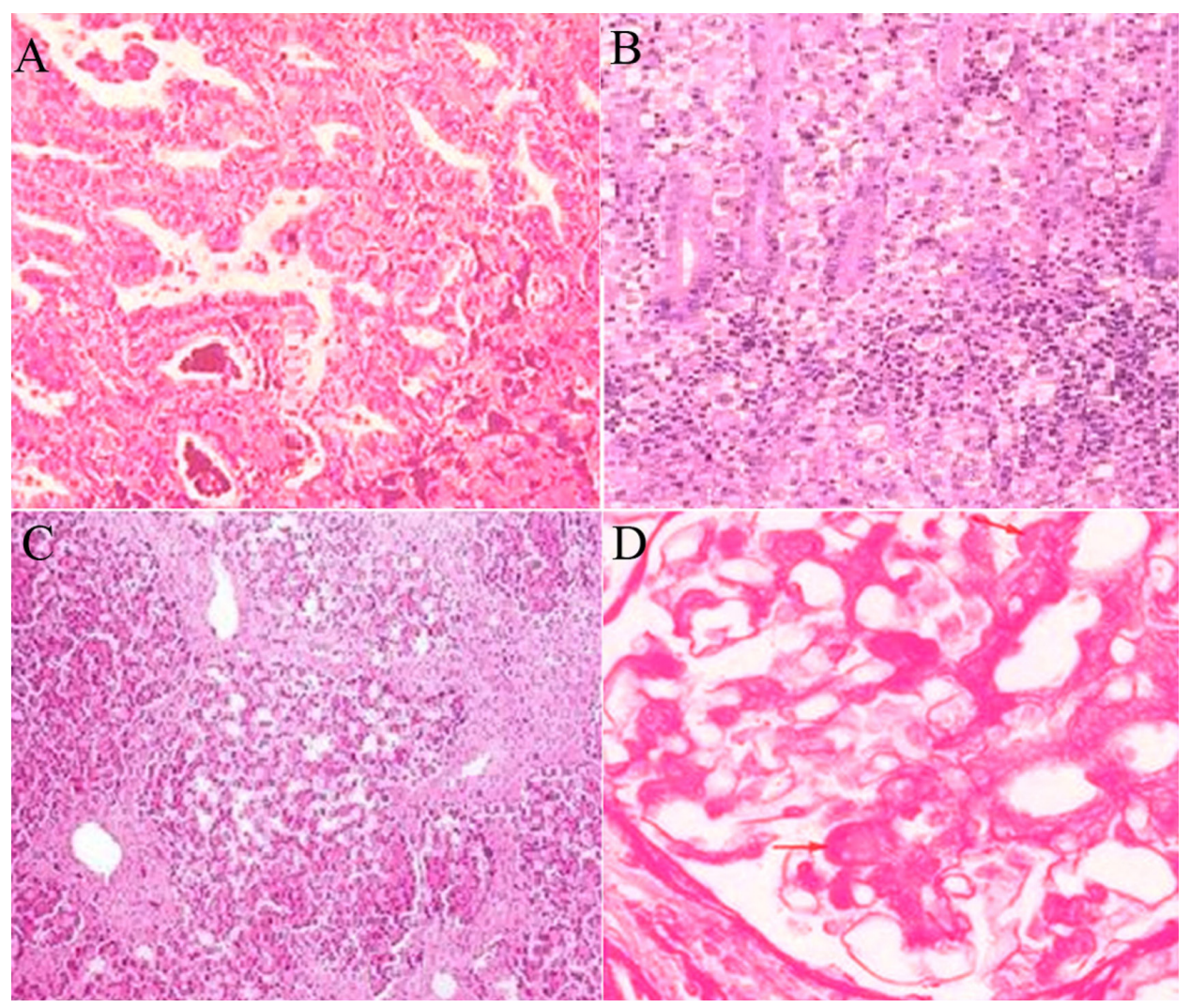

Figure 1. Pathological changes of main organs in the subarachnoid hemorrhage (SAH) group. A. Pathological changes of lung tissues $24 \mathrm{~h}$ after hemorrhage (SP 400X). B. Pathological changes of small intestine tissues $36 \mathrm{~h}$ after hemorrhage (SP 400X). C. Pathological changes of liver tissues $24 \mathrm{~h}$ after hemorrhage (SP 400X). D. Pathological changes of kidney tissues $36 \mathrm{~h}$ after hemorrhage (arrows; SP 400X). 


\section{MVZ protein expression levels}

Both the normal control group and the sham operation group exhibited a small number of lightly stained positive MVZ cells (Figure 2A), between which the difference was not statistically significant $(\mathrm{P}>0.05)$. The number of positive MVZ cells in the SAH group was significantly higher than in the normal control and sham operation groups, in which the majority were deeply stained (Figure 2B). The positive cells were relatively numerous in the nucleus tractus solitarii (NTS), the area postrema, and the dorsal vagal nucleus (DMV) in the dorsomedial region and the lateral reticular nucleus (LRN) in the ventrolateral medulla; they peaked at $24 \mathrm{~h}$ and gradually decreased after 6-48 h, but there was still positive expression at $72 \mathrm{~h}$ (Table 3).

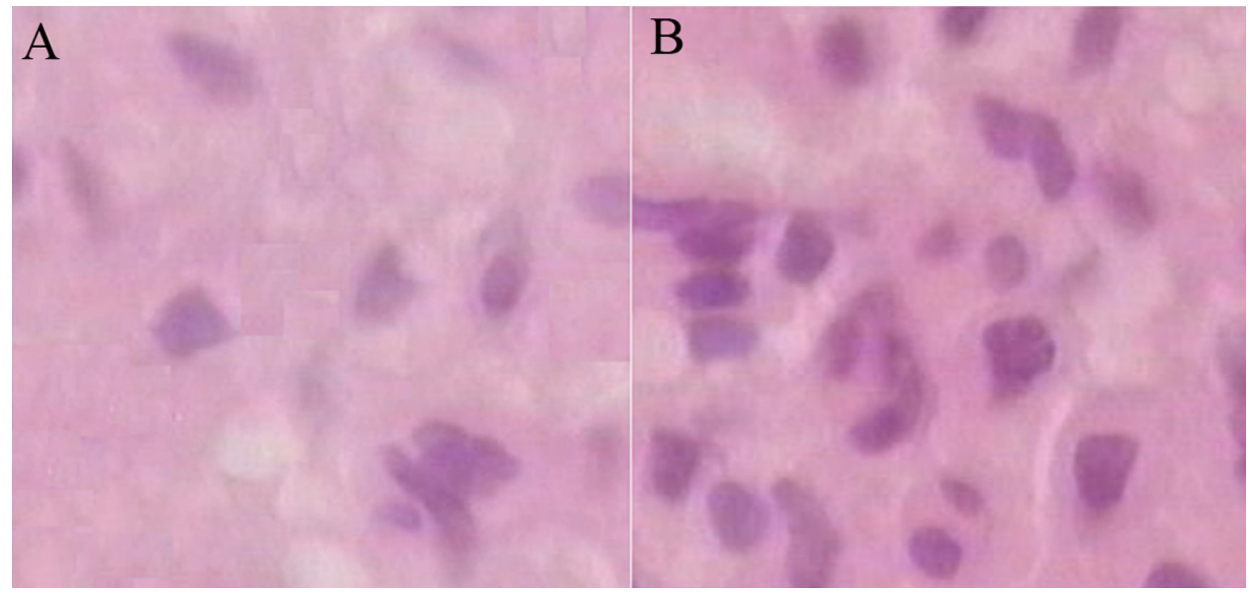

Figure 2. Medullary visceral zone (MVZ) protein expression levels. A. A small number of lightly stained positive MVZ cells in the ventrolateral medulla (VLM) of the sham operation group (SP 400X). B. Numerous darkly stained positive MVZ cells in the VLM of the subarachnoid hemorrhage group (SP 400X).

Table 3. Positive expressions of medullary visceral zone (MVZ) proteins in the ventrolateral medulla (VLM) at each time point.

\begin{tabular}{llc}
\hline Group & $\mathrm{N}$ & Number of positively expressed MVZ proteins \\
\hline Normal & 10 & $8.46 \pm 2.07$ \\
Sham operation & 10 & $9.38 \pm 2.43$ \\
SAH & 10 & $34.51 \pm 4.65^{* *}$ \\
$\quad 6 \mathrm{~h}$ & 10 & $59.16 \pm 6.29^{* *}$ \\
$12 \mathrm{~h}$ & 10 & $98.32 \pm 10.65^{\# *}$ \\
$24 \mathrm{~h}$ & 10 & $88.49 \pm 7.59^{* *}$ \\
$36 \mathrm{~h}$ & 10 & $67.56 \pm 7.18^{* *}$ \\
$78 \mathrm{~h}$ & 10 & $42.65 \pm 4.69^{* *}$ \\
\hline
\end{tabular}

Data are reported as means $\pm \mathrm{SE}$. $\mathrm{SAH}=$ subarachnoid hemorrhage. Compared with the normal group, ${ }^{\#} \mathrm{P}<0.01$; compared with the sham operation group, $* \mathrm{P}<0.01$.

\section{DISCUSSION}

Recent studies have found that there is a ribbon called the MVZ that runs from the dorsomedial to the ventrolateral region on the transverse section of the middle and tail of the 
rat medulla oblongata. The MVZ, an important center for the regulation of stress response, is closely related to the transmission of somatic and visceral sensitivity and the regulation of visceral activities, exerting a strong influence on the surrounding organs during ACVD (Jiang et al., 2009; Yang et al., 2010a). Protein is expressed in the MVZ in the early stages of ACVD. As a cell transcription regulatory factor, the MVZ protein is involved in the transcription process of all enzymes effected by the signal transduction system. Many studies have confirmed that the MVZ protein, which fulfills a "tracer" role, can be used as a positioning and functional indicator of neuronal activity (Treger et al., 2008; He et al., 2013). Zhao et al. (2011) replicated MODS caused by cerebral hemorrhage in a rat model using different doses $(0.5$ and $1.0 \mathrm{U})$ of collagenase and found that the positive expression of MVZ protein increased after cerebral hemorrhage compared with the control group, and the number of positively expressing MVZ cells was significantly higher in the $1.0 \mathrm{U}$ group than in the $0.5 \mathrm{U}$ group. Thus, it can be seen that severe ACVD may cause changes in MVZ protein expression in the central nervous system, and to a certain extent the quantity of protein induced is related to the stimulation intensity suffered. Studies have shown that after rats were given $1 \%$ formaldehyde by intragastric administration, bulbar MVZ immunoreactive neurons were mainly located in the NTS ventrolateral region of the middle and tail and the reticular structure between the two, and the number of MVZ/tyrosine hydroxylase double-positive neurons accounted for more than $50 \%$ of the total number of tyrosine hydroxylase single-positive neurons, suggesting that more than half of the catecholaminergic neurons in the MVZ are involved in the stress response to noxious stimuli in the digestive tract (Gallas et al., 2011). In this study, the rats in the SAH group exhibited inflammatory damage in the small intestine $24 \mathrm{~h}$ after SAH, which reached a peak between 36 and $48 \mathrm{~h}$, and was significantly alleviated after $72 \mathrm{~h}$. This is consistent with the MVZ expression pattern after SAH, especially the intensive expression of MVZ protein in the DMV. This prompts the suggestion that the functions of NTS and DMV are affected after SAH, causing inflammatory damage of the intestinal mucosa and submucosa (Yang et al., 2010b).

Using the cardiovascular stress response model of hypertension and acute myocardial ischemia induced by intravenous injection of Pituitrin, some researchers found that MVZ protein expression was limited to the MVZ region, and was negative in the surrounding nuclei. Its expression was more intensive in the NTS and ventrolateral medulla, in which $50 \%$ of neurons were MVZ/tyrosine hydroxylase double-positive, indicating that the catecholaminergic neurons in MVZ are involved in the stress response to cardiovascular noxious stimuli (Rotoli et al., 2011; Daubert et al., 2012). In view of the limited experimental conditions, this study did not investigate the changes of blood pressure and electrocardiogram measurements in the rats after SAH, but the changes in heart rate and myocardial enzymes did reflect myocardial ischemia. In this study, the MVZ protein was markedly expressed $6 \mathrm{~h}$ after hemorrhage in the SAH group, and was mainly distributed in the NTS, LRN, and DMV, and to a lesser extent in the area postrema. The protein expression peaked after $24 \mathrm{~h}$, but was still relatively intensive after $36 \mathrm{~h}$ and gradually subsided after $72 \mathrm{~h}$. The positive expression of MVZ protein was consistent with the changes of heart rate and myocardial enzymes, prompting the suggestion that positive MVZ protein expression is associated with peripheral myocardial ischemia. Therefore, it is inferred that the MVZ participates in the regulation of heart function after SAH.

Electric damaged the NTS in the MVZ of rats can lead to neurogenic pulmonary edema. It is thought that the ascending fibers of the caudal NTS have a wide range of fiber links to catecholaminergic neurons in the brainstem reticular structure, so as to cause neurogenic pulmonary edema by regulating the release of catecholamines (Mukadam et al., 2005; 
Schreiber et al., 2007). This study found that the breathing frequency at each time point was significantly faster in the SAH group compared with the control group, the difference being more pronounced at 24,36 , and $48 \mathrm{~h}$. In addition, non-specific pulmonary inflammation also appeared $6 \mathrm{~h}$ after SAH, reached a peak between 24 and $36 \mathrm{~h}$, and subsided after $48 \mathrm{~h}$. At the same time, the positive expression of MVZ protein could also be found at the same regular pattern, and was most pronounced in the caudal NTS and LRN. In the SAH group, MVZ-positive expression in the sites mentioned above appeared at $6 \mathrm{~h}$, peaked at $24 \mathrm{~h}$, was still sustained at a relatively high level at $36 \mathrm{~h}$, and began to subside gradually at $48 \mathrm{~h}$, which prompts the suggestion that a series of cerebral pathophysiological changes after SAH can affect the NTS and LRN functions in MVZ, so that the regulation of respiratory function of the lung becomes unbalanced under normal circumstances, thereby causing neurogenic pulmonary edema.

The mechanism of ACVD-induced MODS is complicated. This study found that there is an obvious relationship over time between MVZ protein expression and pathological changes in myocardial enzymes and the surrounding vital organs following SAH. Therefore, there may be a necessary relationship between them, suggesting that the MVZ is one of the direct regulative centers in SAH-induced MODS, and is involved in the functional regulation of the surrounding organs following SAH.

\section{Conflicts of interest}

The authors declare no conflict of interest.

\section{REFERENCES}

Abdo AA, Castellanos R, Rocha M, Hernández E, et al. (2012). Continuous venovenous hemodiafiltration in patients with multiple organ dysfunction syndrome in an intensive care unit. MEDICC Rev. 14: 26-30.

Arauz A, Murillo-Bonilla L, Leyva A, Barinagarrementeria F, et al. (2010). Guideline for secondary prevention treatment in cerebrovascular diseases after acute phase. Rev. Invest. Clin. 62: 130-134.

Daubert DL, McCowan M, Erdos B and Scheuer DA (2012). Nucleus of the solitary tract catecholaminergic neurons modulate the cardiovascular response to psychological stress in rats. J. Physiol. 590: 4881-4895.

Gallas S, Sinno MH, Boukhettala N, Coëffier M, et al. (2011). Gastric electrical stimulation increases ghrelin production and inhibits catecholaminergic brainstem neurons in rats. Eur. J. Neurosci. 33: 276-284.

He Y, Qu QC, Wang BX, Du FY, et al. (2013). FOS protein expression and role of the vagus nerve in the rat medullary visceral zone in multiple organ dysfunction syndrome caused by subarachnoid hemorrhage. Exp. Ther. Med. 5: 223-228.

Jiang H, Wang M, Guo J and Li Z (2009). The midnight-noon ebb-flow point selection for 30 cases of acute ischemic cerebrovascular diseases. J. Tradit. Chin. Med. 28: 193-197.

Koton S, Tashlykov V, Schwammenthal Y, Molshatzki N, et al. (2012). Cerebral artery calcification in patients with acute cerebrovascular diseases: determinants and long-term clinical outcome. Eur. J. Neurol. 19: 739-745.

Mukadam ME, Harrington DK, Wilson IC, Mascaro JG, et al. (2005). Does donor catecholamine administration affect early lung function after transplantation? J. Thorac. Cardiovasc. Surg. 130: 926-927.

Ozel H, Yuksel BC, Berkem H, Avsar FM, et al. (2009). The effects of L-NG-nitroarginine in a zymosan-induced multiple organ dysfunction syndrome model. Eur. Surg. Res. 43: 211-218.

Rösler N, Berge T and Ritzki M (2010). German diagnosis related groups (G-DRG): results of sociomedical expertises in acute cerebrovascular diseases. Gesundheitswesen 72: 419-424.

Rotoli G, Grignol G, Hu W, Merchenthaler I, et al. (2011). Catecholaminergic axonal varicosities appear to innervate growth hormone-releasing hormone-immunoreactive neurons in the human hypothalamus: the possible morphological substrate of the stress-suppressed growth. J. Clin. Endocrinol. Metab. 96: E1606-E1611.

Schreiber T, Hueter L, Gaser E, Schmidt B, et al. (2007). Effects of a catecholamine-induced increase in cardiac output on lung injury after experimental unilateral pulmonary acid instillation. Crit. Care Med. 35: 1741-1748.

Treger I, Ring H, Schwartz R, Tsabari R, et al. (2008). Hospital disposition after stroke in a national survey of acute cerebrovascular diseases in Israel. Arch. Phys. Med. Rehabil. 89: 435-440. 
Whiteley W, Wardlaw J, Dennis M, Lowe G, et al. (2011). Blood biomarkers for the diagnosis of acute cerebrovascular diseases: a prospective cohort study. Cerebrovasc. Dis. 32: 141-147.

Yang HY, Guo TT, Ma YN, Liu TY, et al. (2010a). Effects of $650 \mathrm{~nm}$ laser and moxibustion pretreatment on enteric nervous system and medullary visceral zone in rats with visceral traction pain. Zhongguo Zhen Jiu 30: 745-751.

Yang Z, Rao Z, Jiang X, Yuan H, et al. (2010b). Reciprocal pathway between medullary visceral zone and hypothalamic supraoptic nucleus or paraventricular nucleus involved in hyperosmotic regulation. Cell Biol. Int. 33: 475-482.

Yavuz L, Aynali G, Aynali A, Alaca A, et al. (2012). The effects of adjuvant immunoglobulin M-enriched immunoglobulin therapy on mortality rate and renal function in sepsis-induced multiple organ dysfunction syndrome: retrospective analysis of intensive care unit patients. J. Int. Med. Res. 40: 1166-1174.

Zhao DQ, Lu CL and Ai HB (2011). The role of catecholaminergic neurons in the hypothalamus and medullary visceral zone in response to restraint water-immersion stress in rats. J. Physiol. Sci. 61: 37-45. 